\title{
Implementasi Algoritma Apriori untuk Mencari Asosiasi Barang yang Dijual di E-commerce OrderMas
}

Implementation of Apriori Algorithm to Find Items Association That Sold at OrderMas E-commerce

\author{
Moh.Sholik ${ }^{1}$, Abu Salam ${ }^{2}$, \\ ${ }^{1,2}$ Universitas Dian Nuswantoro; Jl. Nakula I No 5 - 11 Semarang, Telp. (024)3515261, \\ 3520165 Fax: 3569684 \\ e-mail: ${ }^{1}$ sholik1993@gmail.com, ${ }^{2}$ abu.salam@dsn.dinus.ac.id
}

\begin{abstract}
Abstrak
Kekurangan atau kekosongan stok barang pada suatu toko/perusahaan akan berdampak sangat buruk untuk keberhasilan dan kelancaran transaksi jual beli, penyebab terjadinya kekosongan stok adalah tidak adanya informasi yang disampaikan dari perusahaan kepada supplier penyetok barang secara dini. Untuk mencegah hal tersebut maka dibutuhkan sebuah system yang dapat membantu supplier barang agar mengetahui secara dini tentang ketersediaan barang yang terdapat pada toko / perusahaan tertentu. Berdasarkan data transaksi penjualan maka system ini dibangun mnggunakan metode Assosiasi dengan algoritma apriori yang merupakan tehnik dalam data mining untuk menemukan aturan assosiatif kombinasi antara itemset. Perhitungan dilakukan dengan menentukan support dan confidance yang akan menghasilkan assosiasi rules, yang dapat digunakan untuk menentukan stok barang apa saja yang perlu diperbanyak oleh supplier guna meningkatkan keuntungan antara supplier dan perusahaan.
\end{abstract}

Kata kunci- Data mining, assosiasi rule, algoritma apriori, support, confidence.

\begin{abstract}
Lack or emptiness of stock items at a store/company will have an impact is very bad for the successful and smooth transaction of buying and selling, the cause of the occurrence of the vacancy and your stock is the absence of information submitted by the company to supplier distributor stuff early. To prevent these things then it needs a system that can help suppliers of goods in order to find out early about the availability of the goods in the store/company. Based on sales transactions data then the system was built using the methods Associated with the apriori algorithm is a technique in data mining to discover rules of the assosiation combination of the itemset. The calculation is done by determining the support and confidence that will generate the associated rules, which can be used to determine what stock items that need to be manufactured by the supplier in order to increase profits between supplier and the company.
\end{abstract}

Keywords- Data mining, association rule, apriori algorithm, support, confidence. 


\section{PENDAHULUAN}

Ketika sebuah toko memiliki stok barang yang lebih banyak daripada jumlah yang diminta konsumen, maka toko akan mengalami kerugian, karena stok barang tidak laku dan habis terjual, terutama barang-barang yang mengandung unsur kadaluwarsa dan mudah rusak. Sebaliknya apabila suatu toko/perusahaan memiliki stok barang yang minimum dibandingkan dengan jumlah permintaan maka berakibat pada toko/ perusahaan yaitu konsumen tersebut akan pergi karena barang yang akan dibeli oleh konsumen tidak mencukupi (opportunity loss). Hal yang sering kita jumpai adalah saat konsumen ingin membeli suatu barang dan barang yang ingin dibeli ternyata habis, maka konsumen akan membeli ketempat lain dan untuk waktu yang akan datang konsumen akan lebih banyak mempertimbangkan jika ingin membeli ditoko itu kembali, karena takut barang yang diinginkan habis kembali, tentunya hal ini dapat mengurangi tingkat penjualan. Guna mengatasi masalah tersebut maka dibutuhkan suatu system cerdas data mining yang dapat membantu guna mengambil keputusan berhubungan jenis dan stok barang yang disediakan pada Supply Chain berikutnya menggunakan data mining [1].

Data mining berguna untuk memberikan solusi kepada para pemilik perusahaan untuk mengambil keputusan guna meningkatkan bisnis perusahaan. Dengan menggunakan analisis asosiasi dan algoritma apriori dapat menghasilkan suatu rekomendasi yang di harapkan dapat membantu manager dalam mendukung keputusan strategi penjualan [2]. Jadi data maning adalah suatu proses tentang pengambilan data ataupun informasi dalam sekala besar dan kemudian dapat diproses menjadi sebuah pengetahuan untuk mendapatkan informasi yang akurat tanpa melalui perhitungan manual [3]. Salah satu hal penting dalam teknik data mining adalah aturan untuk menemukan pola frekuensi tinggi antar himpunan itemset yang disebut dengan fungsi Association Rules (aturan asosiasi) [4][5][6]. Perkembangan teknologi pada data mining tersebut dapat digunakan untuk menganalisa data dan memprediksi jumlah barang [7].

Dalam sebuah penelitian yang berjudul Analisa Data Mining Dalam Penjualan Sparepart Mobil dengan Menggunakan Metode Algoritma Apriori, proses asosiasi menggunakan algoritma apriori menghasilkan aturan asosiasi keterkaitan yang kuat antar itemset penjualan suku cadang sehingga bisa memberi rekomendasi penyetokan barang dan mempermudah dalam penataan atau penempatan barang yang kuat berkaitan saling ketergantungan [8], Denny Haryanto juga melakukan penelitian pada market basket analysis dengan melakukan pencarian pola relasi penjualan terlebih dahulu sebelum melakukan penawaran, maka penawaran barang yang berpeluang kecil untuk terbeli akan terabaikan untuk ditawarkan [2]. Dalam penelitian lain penerapan data mining untuk market basket analisys menggunakan algoritma Apriori dapat membantu menemukan pola penjualan obat berdasarkan kecenderungan obat yang terjual secara bersamaan, kemudian dari hasil pengujian ini juga dapat membantu pihak apotek dalam mengatur tata letak obat secara berdekatan untuk memudahkan dalam mengetahui keberadaan obat serta dapat membantu dalam mengambil keputusan untuk menentukan persediaan obat [9][10][11]. Penelitian Association rule dalam penjualan barangbarang kesehatan juga pernah dilakukan untuk mengetahui pola penjualan yang digunakan sebagai dasar pengambilan keputusan dalam menyiapkan barang yang diprioritaskan dalam penjualan kedepan[12], Penelitian Association rule juga digunakan untuk mengetahui produk dengan penjualan terbanyak dan keterkaitan produk satu dengan yang lainnya berdasarkan kondisi transaksi yang dilakukan. [13][14][15][16][17].

Penelitian ini bertujuan menganalisis data transaksi penjualan di e-commerce OrderMas untuk mencari keterkaitan pembelian antar item guna memecahkan masalah tentang pengadaan stok barang oleh supplier OrderMas yang tidak dapat di prediksi kapan supplier harus menyetok barang tersebut, serta berguna untuk penataan barang pada e-commerce OrderMas dengan kecenderungan pola pembelian konsumen . 


\section{METODE PENELITIAN}

Analisis implementasi algoritma apriori untuk mencari asosiasi barang yang dijual pada ecommerce OrderMas akan diselesaikan melalui beberapa tahapan dengan melihat dari literature review, pengumpulan data, kebutuhan yang dibutuhkan, pengujian data dan analisis. Alur yang digunakan dalam penelitian ini adalah sebagai berikut :

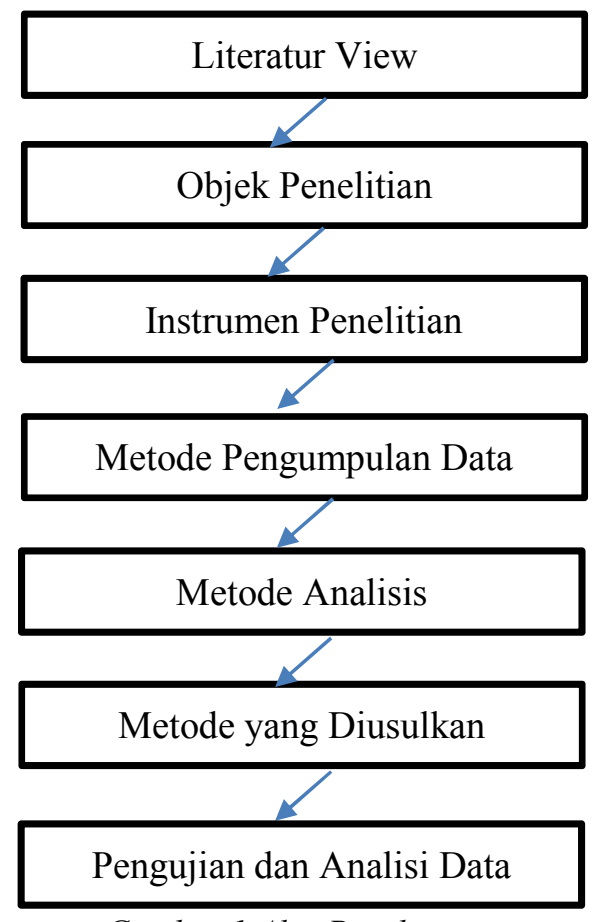

Gambar 1 Alur Penelitian

\subsection{Literature View}

Penulis menggunakan jurnal ilmah, proceedings dan e-book diantaranya adalah "Decision Support on Supply Chain Management System Using Apriori Data Mining Algorithm "[1], "Applications Of Data Mining Techniques In Pharmaceuntical Industry" [3] dan jurnal ilmiah ISSN yang berjudul "Analisa Data Mining Dalam Penjualan Sparepart Mobil dengan Menggunakan Metode Algoritma Apriori”[8], "Data Mining Market Basket Analysis Menggunakan Algoritma Apriori Untuk menentukan Persediaan Obat" [10], serta e-book yang berjudul "Data Mining : Practical Machine Learning Tools and Techniques 3rd Edition" [6], "Discovering Knowledge in Data, an Introduction to Data Maning" [5], "Data Mining: Concepts and Techniques Third Edition" [4], dan juga beberapa jurnal internasional maupun nasioanal yang mengenai data mining serta ketersediaan dan keterkaitan antar barang menggunakan algoritma apriori lainnya.

\subsection{Objek Penelitian}

Pada penelitian ini objek yang akan dijadikan penelitian oleh penulis adalah project Web E-commerce Semarang, Jawa Tengah. Dengan mengambil data dari dataset di internet untuk penelitian, dikarenakan belum adanya transaksi paada web E-ommenrce tersebut sedangkan transaksi digunakan lebih kurangnya 1000 record data.

\subsection{Instrumen Penelitian}

Instrumen peralatan yang digunakan untuk penelitian ini meliputi perangkat keras (Hardware) dan perangkat lunak (software) sebagai berikut:

1. Perangkat Keras (Hardware) meliputi : 

a. Laptop Dell Inspiron N-4050 Prosesor Intel core i3-6006U
b. CPU dengan kecepatan @2,0GHz
c. RAM 6 GB
d. Harddisk $500 \mathrm{~GB}$
e. Layar 14 inch

2. Perangkat Lunak (software) meliputi :
a. Delphy 7 , digunakan untuk mengolah data mentah menjadi data tabular agar data bisa diolah di aplikasi RapidMiner.
b. Data Base FireBird, Sistem Manjemen Basis data Relasional untuk database Delphy 7
c. Rapid Miner, Rapid Miner adalah salah satu sofwere yang digunakan untuk membangun sistem ini sebagai pengolah data dan menampilkan hasil yang ada.
d. Microsof Excel, Untuk mempermudah mengumpulkan data dan menampung data hasil extrasi dari program delphy.

\subsection{Metode Pengumpulan Data}

Metode yang digunakan adalah metode Survei dimana mengacu kepada metode pengamanan informasi mengenai fenomena yang diteliti dari seluruh populasi atapun sampel yang mewakili melalui pengamatan. Penulis juga menggunakan metode wirrelesnet dan website yaitu pengumpulan data-data melalui internet yaitu set data transnasional yang berisi semua transaksi yang terjadi antara 01/12/2010 dan 09/12/2011 untuk bebas-toko ritel online berbasis di Inggris dan terdaftar.

\subsection{Metode Analisis}

Data yang telah didapat dan dikumpulkan selama proses pencariaan dan pengumpulan data kemudian akan masuk ketahap selanjutnya yaitu tahap analisis data. Metode analisis data ini yaitu dengan proses membedakan data sesuai dengan jenisnya, adapun macam dan jenis data antara lain data primer dan data sekunder.Disini data yang digunakan adalah data Sekunder Perngertian atau penjelasan data sekunder merupakan data yang didapat dari proses pencarian data online shop retail yang berbasis di inggris melalui internet, data ini lah yang nantinya akan dijadikan sebagai acuan dalam proses pengembangan sistem data mining. Selanjutnya pengertian data sekunder merupakan data-data yang terkumpul melalui proses analisis literatur, buku, jural, atau internet yang semua memiliki hubungan dengan data mining. Semua data-data tersebut akan dianalisis agar dapat digunakan sesuai dengan metode perhitungan yang akan peneliti gunakan.

\subsection{Metode Yang Diusulkan}

Melakukan pelatihan pada set data menggunakan algortima apriori dengan cara metode association rule untuk menentukan pengelompokan data, Teknik association rule yaitu cara dalam data mining untuk menemukan rule dalam kombinasi tertentu untuk satu item. Didalam teknik association rule ada 2 parammeter antara lain adalah confidence dan support. Support yaitu hasil dari nilai yang ditunjang untuk dilihat dengan tingkatan presentasi dalam itemset tersebut dari keseluruhan transakisi yang dilakukan, sedangkan confidence merupakan suatu hasil kepastian yang dapat dilihat kuat tidaknya relasi dengan itemset tersebut merupakan association rule.[4][6].

Algoritma apriori yaitu salah satu algoritma yang diajukan Agrawal dan Srikant tahun 1994 yang berfungsi untuk menentukan frequent itemset pada asosiasi boolean [4]. Algoritma ini bertugas unuk memantau perkembangan kandidat dari itemset tersebut [2]. Pseudo-Code Apriori Algorithm: 


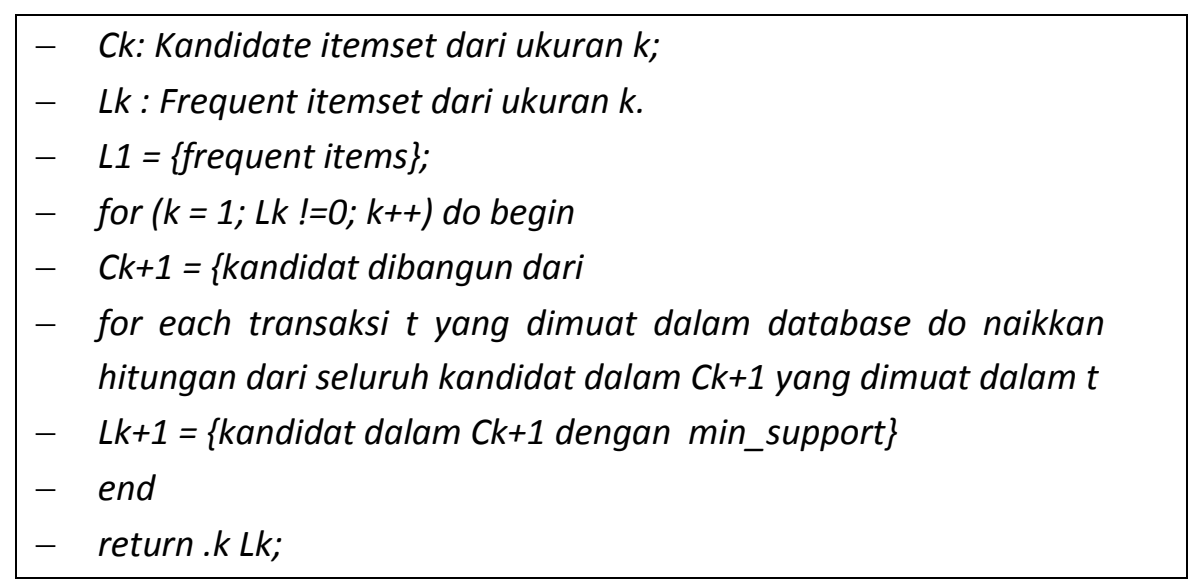

\subsection{Pengujian Implementasi Data Mining}

Knowledge Discovery in Databases (KDD) merupakan sebutan lain dari tahapan data mining. Langkah pertama untuk mengolah data yaitu seleksi data, yang kedua adalah pembersihan data, ketiga pembersihan data, keempat transformasi data, terakhir data mining dan evaluasi [18][19].

\section{- Seleksi Data}

Data utama dalam penelitian ini yaitu data transksi penjualan online shoop retail yang berbasis di Inggris diambil pada periode 01/12/2010-31/12/210 atau \pm 1 bulan transaksi.

- Praproses Data /Pembersihan Data

Pada tahap ini merupakan tahap yang dapat dikatakan sebagai tahap pembersihan data. Data pertama yang terkumpul biasanya masih banyak terdapat data yang kosong, data yang tidak konsisten, atau data yang sama/ kembar. Data yang masih tercakup seperti yang telah dijelaskan selanjutnya akan disaring hingga mandapatkan output data yang benar sesuai dengan yang dibutuhkan untuk proses selanjutnya.

- Transformasi Coding

Setelah melewati proses pembersihan data kemudian data akan di masukan ke dalam proses data mining. Langkah selanjutnya yaitu mengubah data keformat file Comma Separated Values (CSV) yang dapat terintegrasi pada Excel.

- Data Mining

Kemudian tahap data mining, selanjutnya proses untuk mengolah data menggunakan algoritma. Dalam penelitian ini algoritma apriori dipilih sebagai solusi untuk pengolahan data. Contoh implementasi seperti pada gambar dibawah ini.

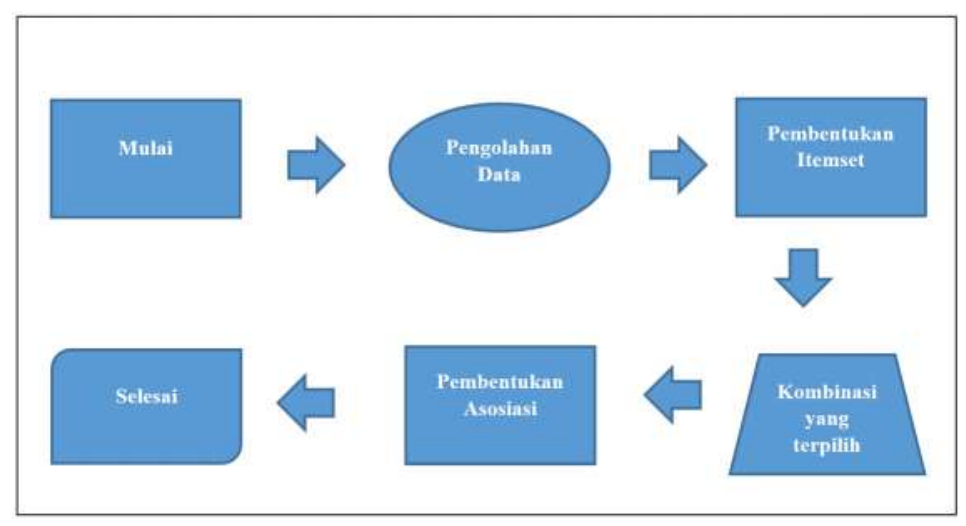

Gambar 2 Proses Data mining Algoritma Apriori 
- Interpretation/Evaluasi

Hasil akhir dari proses data mining agar pola informasi dapat dimengerti oleh pihak perusahaan ataupun supplier dapat ditampilkan dalam bentuk sederhana dan mudah dimengerti. Evaluasi yang berjalan pada tahapan ini merupakan memeriksa ulang dan membandingkan data atau informasi yang dirasa berbeda dengan data fakta yang ada dilapangan.

\section{HASIL DAN PEMBAHASAN}

Tahapan awal yang dilakukan pada penelitian ini adalah mempersiapkan data, persiapan data yang akan diolah merupakan data public yang sama dengan dataset OrderMas, dataset tersebut diperoleh dari internet yaitu dataset Online Retail yang berbasis di Inggris. Kemudian total jumlah data yang digunakan untuk penelitian yaitu diambil sebanyak lebih kurangnya 10.000 record data. Data-data tersebut merupakan data transaksi penjualan barang.

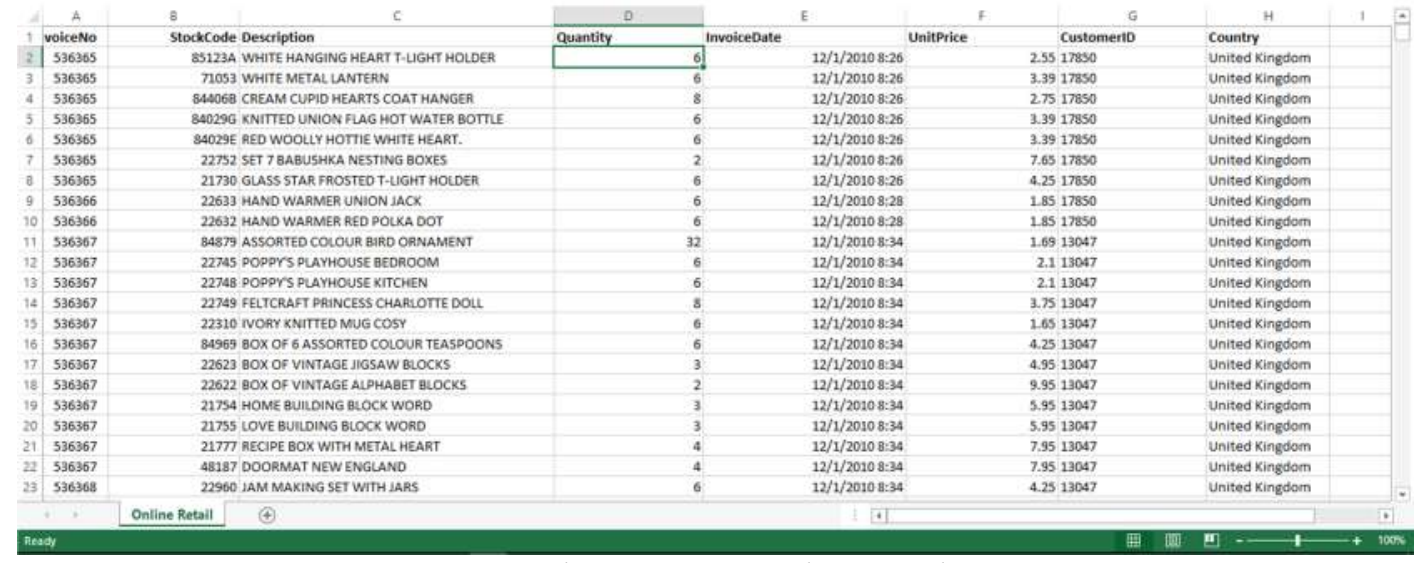

Gambar 3 Dataset Online Retail

Pada proses ini data akan disaring dan dirubah menjadi data tabular oleh aplikasi yang sudah dibuat di delphy7 sehingga menjadi data yang siap untuk diolah dalam proses sistem data mining dengan algoritma apriori. Dari data yang berjumlah lebih kurang 10.000 record data, setelah disaring data yang siap digunakan berjumlah 324 record data dengan atribut yang digunakan yaitu:

1. Cutomer ID (id konsumen)

2. Discription (nama barang)

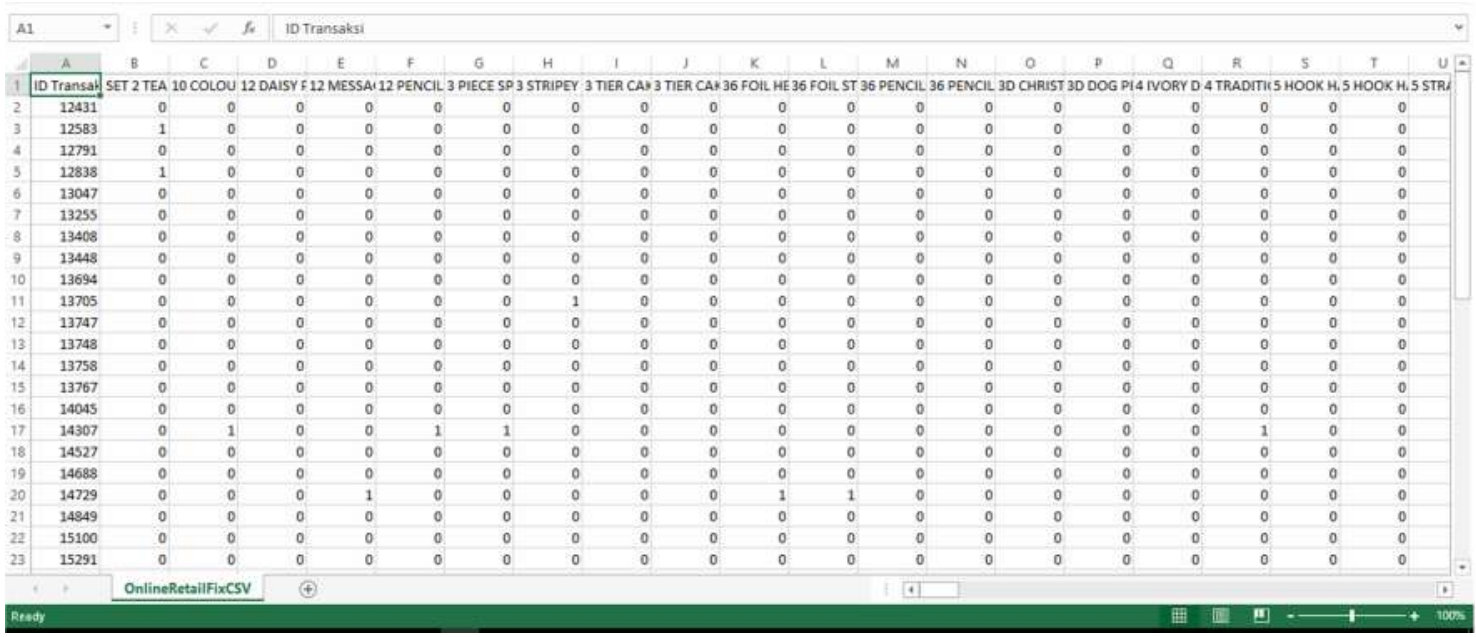

Gambar 4 Dataset Online Retail dengan Dua Atribut 
Pada gambar diatas dapat dijelaskan penulis merubah dataset awal yang memiliki beberpa atribut dan dirubah melalui proses aplikasi sehingga didapat 2 atribut yang akan digunakan untuk langkah penelitian selanjutnya.

Langkah selanjutnya adalah transformasi coding, merupakan pengolahan data yang berjumlah 324 record yang dilakukan dengan memasukkan data kedalam aplikasi RapidMiner kemudian system mengolahnya dengan algoritma apriori dengan metode association rules untuk mendapatkan hasil akhir sesuai yang diharapkan.

\subsection{Analisis Data Mining}

Sebagai perhitungan tentang algoritma apriori dengan metode assosiasi penulis menggambil data yang akan diolah sebagai contoh yaitu sebanyak 10 data penjualan barang seperti terlihat pada table dibawah. Penulis memberikan batasan nilai minimum support 0.5 atau sama dengan $50 \%$. dan confidence 0.5 atau sama dengan $50 \%$.

Berikut ini merupkan sampel data barang yang sudah dijelaskan pada table.

Tabel 1 Data Barang

\begin{tabular}{|c|c|c|}
\hline No & Kode Barang & Nama Barang \\
\hline 1 & A1 & WHITE METAL LANTERN \\
\hline 2 & A2 & PINK FAIRY CAKE CHILDRENS APRON \\
\hline 3 & A3 & MAGIC DRAWING SLATE PURDEY \\
\hline 4 & A4 & SPACEBOY LUNCH BOX \\
\hline 5 & A5 & VICTORIAN SEWING KIT \\
\hline 6 & A6 & DOODLAND CHARLOTTE BAG \\
\hline 7 & A7 & ALARM CLOCK BAKELIKE GREEN \\
\hline 8 & A8 & DOORMAT FAIRY CAKE \\
\hline 9 & A9 & MINT KITCHEN SCALES \\
\hline 10 & A10 & \\
\hline
\end{tabular}

Data diatas merupakan sample data barang yang akan digunakan pada penelitian ini dan berlaku untuk semua jenis. Akumulasi transaksi penjualan barang dapat dilihat sebagai berikut :

Tabel 2 Data Transaksi

\begin{tabular}{|c|c|}
\hline Transaksi & Barang yang dibeli (berdasarkan kode barang) \\
\hline 1 & $\mathrm{~A} 2, \mathrm{~A} 4, \mathrm{~A} 5, \mathrm{~A} 8, \mathrm{~A} 9$ \\
\hline 2 & $\mathrm{~A} 1, \mathrm{~A} 6, \mathrm{~A} 7, \mathrm{~A} 9$ \\
\hline 3 & $\mathrm{~A} 1, \mathrm{~A} 2, \mathrm{~A} 3, \mathrm{~A} 4, \mathrm{~A} 7, \mathrm{~A} 8, \mathrm{~A} 9, \mathrm{~A} 10$ \\
\hline 4 & $\mathrm{~A} 2, \mathrm{~A} 6, \mathrm{~A} 7, \mathrm{~A} 8, \mathrm{~A} 9$ \\
\hline 5 & $\mathrm{~A} 1, \mathrm{~A} 2, \mathrm{~A} 3, \mathrm{~A} 4, \mathrm{~A} 6, \mathrm{~A} 7, \mathrm{~A} 8, \mathrm{~A} 9, \mathrm{~A} 10$ \\
\hline 6 & $\mathrm{~A} 3, \mathrm{~A} 4, \mathrm{~A} 5, \mathrm{~A} 8, \mathrm{~A} 10$ \\
\hline 7 & $\mathrm{~A} 2, \mathrm{~A} 4, \mathrm{~A} 5, \mathrm{~A} 7$ \\
\hline 8 & $\mathrm{~A} 1, \mathrm{~A} 7, \mathrm{~A} 8, \mathrm{~A} 9$ \\
\hline 9 & $\mathrm{~A} 2, \mathrm{~A} 3, \mathrm{~A} 9, \mathrm{~A} 10$ \\
\hline 10 & $\mathrm{~A} 1, \mathrm{~A} 6, \mathrm{~A} 8, \mathrm{~A} 10$ \\
\hline
\end{tabular}

Pada data transaksi penjualan barang dibentuk tabel tabular yang akan memudahkan dalam mengetahui beberapa banyak item yang dibeli disetiap tansaksi. 
Tabel 3 Data Transaksi Tabular

\begin{tabular}{|c|c|c|c|c|c|c|c|c|c|c|}
\hline Transaksi & A1 & A2 & A3 & A4 & A5 & A6 & A7 & A8 & A9 & A10 \\
\hline 1 & 0 & 1 & 0 & 1 & 1 & 0 & 0 & 1 & 1 & 0 \\
\hline 2 & 1 & 0 & 0 & 0 & 0 & 1 & 1 & 0 & 1 & 0 \\
\hline 3 & 1 & 1 & 1 & 1 & 0 & 0 & 1 & 1 & 1 & 1 \\
\hline 4 & 0 & 1 & 0 & 0 & 0 & 1 & 1 & 1 & 1 & 0 \\
\hline 5 & 1 & 1 & 1 & 1 & 1 & 0 & 1 & 1 & 1 & 1 \\
\hline 6 & 0 & 0 & 1 & 1 & 1 & 0 & 0 & 1 & 0 & 1 \\
\hline 7 & 0 & 1 & 0 & 1 & 1 & 0 & 1 & 0 & 0 & 0 \\
\hline 8 & 1 & 0 & 0 & 0 & 0 & 0 & 1 & 1 & 1 & 0 \\
\hline 9 & 0 & 1 & 1 & 0 & 0 & 0 & 0 & 0 & 1 & 1 \\
\hline 10 & 1 & 0 & 0 & 0 & 0 & 1 & 0 & 1 & 0 & 1 \\
\hline
\end{tabular}

Penyelesaian berdasarkan tabel yang ada pada tabel 2 proses pembuatan $\mathrm{C} 1$ atau bisa dikatakan dengan 1 item dan jumlah minimum support $=50 \%$.

Tabel 4 Support dari Setiap Barang

\begin{tabular}{|c|c|c|}
\hline Kode Barang & Proses Support & Support \\
\hline A1 & $(5 / 10)^{*} 100$ & $50 \%$ \\
\hline A2 & $(6 / 10)^{*} 100$ & $60 \%$ \\
\hline A3 & $(4 / 10)^{*} 100$ & $40 \%$ \\
\hline A4 & $(5 / 10)^{*} 100$ & $50 \%$ \\
\hline A5 & $(3 / 10)^{*} 100$ & $30 \%$ \\
\hline A6 & $(4 / 10)^{*} 100$ & $40 \%$ \\
\hline A7 & $(6 / 10)^{*} 100$ & $60 \%$ \\
\hline A8 & $(7 / 10)^{*} 100$ & $70 \%$ \\
\hline A9 & $(7 / 10)^{*} 100$ & $70 \%$ \\
\hline A10 & $(5 / 10)^{*} 100$ & $50 \%$ \\
\hline
\end{tabular}

Dari Proses pembentukan item pada tabel 4.4 dengan minimum support 50\% dapat diketahui yang memenuhi standar minimum support yaitu ada 7 Jenis, dari ke 7 jenis tersebut kemudian dibentuk kombinasi item 2 item. Tabel berikut merupakan jenis item yang memenuhi standart minimum support :

Tabel 5 Data Barang yang Memenuhi Support

\begin{tabular}{|c|c|}
\hline Kode Barang & Support minimal 50\% \\
\hline A1 & $50 \%$ \\
\hline A2 & $60 \%$ \\
\hline A4 & $50 \%$ \\
\hline A7 & $60 \%$ \\
\hline A8 & $70 \%$ \\
\hline A9 & $70 \%$ \\
\hline A10 & $50 \%$ \\
\hline
\end{tabular}

Pembentukan $\mathrm{C} 2$ atau bisa dikatakan dengan 2 item dengan jumlah minimum support $=50 \%$ dan dapat terselesaikan dengan rumus Support $(\mathrm{A}, \mathrm{B})=\mathrm{P}(\mathrm{A}$ B) Support(A,B). 
Tabel 6 Data dari 2 itemset dengan Minimum Support 50\%

\begin{tabular}{|c|c|c|c|}
\hline Kode Barang & Jumlah & Proses Support & Support \% \\
\hline A1-A2 & 2 & $(2 / 10) * 100$ & $20 \%$ \\
\hline A1-A3 & 2 & $(2 / 10) * 100$ & $20 \%$ \\
\hline A1-A4 & 2 & $(2 / 10) * 100$ & $20 \%$ \\
\hline A1-A5 & 0 & $(0 / 10) * 100$ & $00 \%$ \\
\hline A1-A6 & 3 & $(3 / 10) * 100$ & $30 \%$ \\
\hline A1-A7 & 4 & $(4 / 10) * 100$ & $40 \%$ \\
\hline A1-A8 & 4 & $(4 / 10) * 100$ & $40 \%$ \\
\hline A1-A9 & 4 & $(4 / 10) * 100$ & $40 \%$ \\
\hline A1-A10 & 3 & $(3 / 10) * 100$ & $30 \%$ \\
\hline A2-A3 & 3 & $(3 / 10) * 100$ & $30 \%$ \\
\hline A2-A4 & 4 & $(4 / 10) * 100$ & $40 \%$ \\
\hline A2-A5 & 2 & $(2 / 10) * 100$ & $20 \%$ \\
\hline A2-A6 & 2 & $(2 / 10) * 100$ & $20 \%$ \\
\hline A2-A7 & 4 & $(4 / 10) * 100$ & $40 \%$ \\
\hline A2-A8 & 4 & $(4 / 10) * 100$ & $40 \%$ \\
\hline A2-A9 & 5 & $(5 / 10) * 100$ & $50 \%$ \\
\hline A2-10 & 3 & $(3 / 10) * 100$ & $30 \%$ \\
\hline A3-A4 & 3 & $(3 / 10) * 100$ & $30 \%$ \\
\hline A3-A5 & 1 & $(1 / 10)^{*} 100$ & $10 \%$ \\
\hline A3-A6 & 1 & $(1 / 10) * 100$ & $10 \%$ \\
\hline A3-A7 & 2 & $(2 / 10) * 100$ & $20 \%$ \\
\hline A3-A8 & 3 & $(3 / 10) * 100$ & $30 \%$ \\
\hline A3-A9 & 3 & $(3 / 10) * 100$ & $30 \%$ \\
\hline A3-A10 & 4 & $(4 / 10) * 100$ & $40 \%$ \\
\hline A4-A5 & 3 & $(3 / 10) * 100$ & $30 \%$ \\
\hline A4-A6 & 1 & $(1 / 10) * 100$ & $10 \%$ \\
\hline A4-A7 & 3 & $(3 / 10) * 100$ & $30 \%$ \\
\hline A4-A8 & 4 & $(4 / 10) * 100$ & $40 \%$ \\
\hline A4-A9 & 3 & $(3 / 10) * 100$ & $30 \%$ \\
\hline A4-A10 & 3 & $(3 / 10) * 100$ & $30 \%$ \\
\hline A5-A6 & 0 & $(0 / 10) * 100$ & $0 \%$ \\
\hline A5-A7 & 1 & $(1 / 10) * 100$ & $10 \%$ \\
\hline A5-A8 & 2 & $(2 / 10) * 100$ & $20 \%$ \\
\hline A5-A9 & 1 & $(1 / 10) * 100$ & $10 \%$ \\
\hline A5-A10 & 1 & $(1 / 10) * 100$ & $10 \%$ \\
\hline A6-A7 & 3 & $(3 / 10)^{*} 100$ & $30 \%$ \\
\hline A6-A8 & 3 & $(3 / 10) * 100$ & $30 \%$ \\
\hline A6-A9 & 3 & $(3 / 10) * 100$ & $30 \%$ \\
\hline A6-10 & 2 & $(2 / 10) * 100$ & $20 \%$ \\
\hline A7-A8 & 3 & $(3 / 10) * 100$ & $30 \%$ \\
\hline A7-A9 & 5 & $(5 / 10) * 100$ & $50 \%$ \\
\hline A7-A10 & 2 & $(2 / 10) * 100$ & $20 \%$ \\
\hline A8-A9 & 5 & $(5 / 10) * 100$ & $50 \%$ \\
\hline A8-A10 & 4 & $(4 / 10) * 100$ & $40 \%$ \\
\hline A9-A10 & 3 & $(3 / 10) * 100$ & $30 \%$ \\
\hline
\end{tabular}

Dari kombinasi 2 itemset dengan minimum support 50\% maka diketahui itemyang memenuhi standart minimum support yaitu sebagai berikut : 
Tabel 7 Data 2 itemset yang Memenuhi Support 50\%

\begin{tabular}{|c|c|c|}
\hline Kode Barang & Nama Barang & Support \\
\hline A2 & PINK FAIRY CAKE CHILDRENS APRON & $50 \%$ \\
\hline A7 & DOORMAT NEW ENGLAND & $50 \%$ \\
\hline A9 & DOORMAT FAIRY CAKE & $50 \%$ \\
\hline
\end{tabular}

Dari kombinasi 2 item akan dibentuk 3 item set dan diambil beberapa proses untuk proses pencarian 3 itemset sebagai berikut:

Tabel 8 Data dengan Kombinasi 3 Itemset

\begin{tabular}{|c|c|c|c|}
\hline Kode Barang & Jumlah Barang & Proses Support & Support \\
\hline A1-A2-A3 & 2 & $(2 / 10)^{*} 100$ & $20 \%$ \\
\hline A3-A4-A5 & 1 & $(1 / 10)^{*} 100$ & $10 \%$ \\
\hline A5-A6-A7 & 0 & $(0 / 10)^{*} 100$ & $0 \%$ \\
\hline A6-A7-A-8 & 2 & $(2 / 10)^{*} 100$ & $20 \%$ \\
\hline A7-A8-A9 & 4 & $(4 / 10)^{*} 100$ & $40 \%$ \\
\hline A8-A9-A10 & 2 & $(2 / 10)^{*} 100$ & $20 \%$ \\
\hline
\end{tabular}

Dalam gabungan tiga item set semua data belum bisa mencakup minimal 50\%, oleh karena itu gabungan dua item set untuk memcukupi dalam bentuk asosiasi.

Hal tersebut untuk memenuhi aturan dan menghitung confidence dalam asosiatif antar item dengan minimum confidence adalah $70 \%$ nilai yang didapat.

Tabel 9 Data Hasil Perhitungan Confidence Asosiasi

\begin{tabular}{|c|c|c|}
\hline Hubungan Antar Item & Proses Confidence & Nilai Confidence \\
\hline A2 $=>$ A9 & $(5 / 5)^{*} 100$ & $100 \%$ \\
\hline A7 $=>$ A9 & $(5 / 6)^{*} 100$ & $83 \%$ \\
\hline
\end{tabular}

Dari tabel diatas menunjukkan nilai asosiasi, bahwa konsumen sering membeli Pink Fairy Cake, Doormat New englang dan Doormat Fairy Cake karena data dari item tersebut telah memenuhi nilai minimum confidance yang ditentukan.

\subsection{Simulasi Data dengan Aplikasi RapidMiner}

Dari hasil proses data menjadi data tabular pada table 3, kemudian akan diproses menggunakan aplikasi RapidMiner dengan extenstion W-apriori akan menghasilkan aturan asosiasi dan beberapa rules berikut ini .

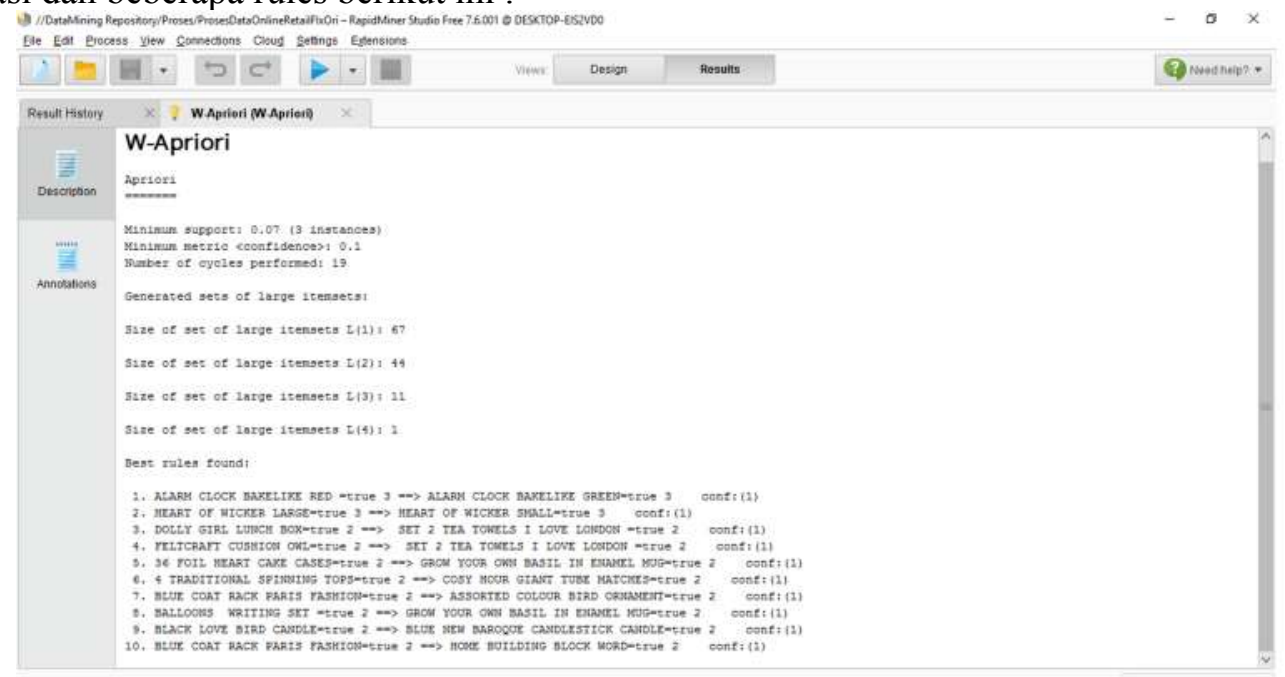

Gambar 5 Rules Hasil Simulasi RapidMiner 
Setelah data melewati tahapan pre-prosesing data oleh RapidMiner, kemudian data dapat diolah dengan menentukan nilai minimal support 50\% dan minimal confidence $50 \%$ dan menentukan jumlah rule yang akan di tampilkan yaitu 10 rules.

\subsection{Hasil dan Evaluasi}

Hasil keseluruhan dari proses implementasi apriori yang disimulasikan pada RapidMiner terhadap data penjualan/transaksi pada dataset OnlineRetail sebanyak 324 data dengan memberikan batasan nilai minimum support dan confidence yang sudah ditentukan, sehingga mendapatkan hasil asosiasi bahwa jenis barang yang paling banyak terjual adalah "Alarm Clock Bakelike Red, Alarm Clock Bakelike Green, Heart of Wicker Large dan Heart of Wicker Small".

Jadi e-commerce OrderMas akan memberikan sebuah informasi/notifikasi kepada supplier yang menjual barang-barang yang paling laku terjual untuk segera menyetok barang tersebut.

Asosiasi apriori akan maksimal apabila semakin tinggi nilai minimum support dan minimunm confidence maka nilai akurasi semakin tinggi pula, karena hanya item-item yang memiliki asosiasi yang kuat dalam pembelian konsumen yang akan dimunculkan dalam hasil perhitungan.

\section{KESIMPULAN}

Berdasarkan pembahasan yang telah dilakukan dengan metode asosiasi dan algoritma apriori serta dilakukanya pengujian dan simulasi dengan aplikasi RapidMiner maka penulis menarik beberapa kesimpul;an yang penting, adapun kesimpulan-kesimpulan tersebut adalah sebagai berikut :

1. Analisis aplikasi yang telah dibangun dengan menggunakan algoritma apriori dengan metode asosiasi, data yang paling banyak muncul pada dataset online retail dengan terpenuhinya nilai minimum support dan minimium confidence yang telah ditentukan oleh penulis.

2. Data Mining Apriori dapat memproses dan di implementasikan dengan menggunakan database transaksi penjulalan online ritail barang, karena dapat menemukan kecenderungan pola kombinasi antar itemsets sehingga dapat dijadikan informasi yang sangat penting dalam pengambilan keputusan yang berguna untuk mempersiapkan jenis stok barang apa yang diperlukan kedepanya.

3. Dari hasil pengujian analisis ini juga dapat membantu pihak e-commerce OrderMas untuk mengatur tata letak barang yang akan dipasarkan di OrderMas yang berguna untuk meningkatkan penjualan barang tersebut dengan mengatur 2 atau 3 itemset barang yang sering dibeli oleh konsumen secara bersamaan.

4. Dengan operator Algoritma W-Apriori yang diuji dengan aplikasi RapidMiner menghasilkan pola kombinasi itemset dan rules sebagai ilmu pengetahuan dan informasi yang bermanfaat dari data penjulan atau transaksi pada suatu toko/perusahaan.

\section{SARAN}

Untuk kepentingan lebih lanjut dari penelitian ini, maka penulis memeberikan beberapa saran yaitu sebagai berikut :

1. Untuk penelitian selanjutnya dengan metode dan algoritma yang sama peneliti dapat menggembangkannya ke dalam objek yang berbeda, dan dengan menggunakan dataset yang lebih besar.

2. Dengan menggunakan dataset yang lebih besar, peneliti dapat menggunakan nilai support dan confidance yang bervariasi, sehingga dapat memperoleh banyak assosiasi rules antar item. 
3. Dalam penggunaan aplikasi RapidMiner untuk analisis data menggunakan $\mathrm{W}$-apriori , banyak tools dan operator yang mempunyai fungsi tertentu, jadi di perlukan pemahaman tentang aturan asosiasi dan Data Mining pada aplikasi RapidMiner.

\section{DAFTAR PUSTAKA}

[1] E. W. Sari, A. Rianto and S. D. Andarawarih, 2014, "Dicision Support on Supply Chain Management System Using Apriori Data Mining Algorithm," IC- ITECHS, pp. 111-117.

[2] D. Haryanto, Y. Oslan and D. Dwiyana, 2011, "Implementasi Analisi Keranjang Belanja Dengan Aturan Asosiasi Menggunakan Algoritma Apriori Pada Penjualan Suku Cadang Sepeda Motor," Jurnal Buana Informatika, pp. 81-94.

[3] J. Ranjan, 2007, "Applications Of Data Mining Techniques In Pharmaceuntical Industry," Journal of Theoretical and Applied Information Technology, Vol.3, pp. 61-67.

[4] J. Han, M. Kamber and J. Pei, 2012, Data Mining: Concepts and Techniques Third Edition, Elsevier.

[5] D. T. Larose, 2015, Discovering Knowledge in Data, an Introduction to Data Maning, Canada: Compain Webite Available.

[6] I. H. Witten, F. Eibe and M. A. Hall, 2011, Data Mining : Practical Machine Learning Tools and Techniques 3rd Edition, Elsevier.

[7] D. A. Verano, 2016, "Assosiasi Rules Dan Moving Average Untuk Memprediksi Persediaan Bahan Baku Produksi," ISBN, p. 2.

[8] K. Ummi, 2015, "Analisa Data Mining Dalam Penjualan SparePart Mobil Dengan Mengg unakan Metode Algoritma Apriori," CSRID Journsl Vol.8 No.3, pp. 155-164.

[9] E. Buulolo, 2013, "Implementasi Algoritma Apriori Pada Sistem Persediaan Obat," Pelita Informatika Budi Darma, vol. 4 No.1, pp. 71-83.

[10]L. Ningsih and D. A. Wulandari, 2017, "Data Mining Market Basket Analysis Menggunakan Algoritma Apriori Untuk menentukan Persediaan Obat," KNIST, pp. 227235.

[11]Y. Rubi and K. R, 2015, "Implementasi Data Mining dengan Metode Algoritma Apriori dalam Menentukan Pola Pembelian Obat," pp, pp. 102-133.

[12]K. Tampubolon, H. Saragih and B. Reza , 2013, "Implementasi Data Mining Algoritma Apriori Pada Sistem Persediaan Alat-alat Kesehatan," Informasi dan Teknologi Ilmiah, pp. 93-106.

[13]M. Badrul, 2016, "Algoritma Asosiasi Dengan Algoritma Apriori Untuk Analisa Data Penjualan," Jurnal Pilar Nusa Mandiri Vol.XII, pp. 121-129.

[14]G. Gunadi and D. I. Sensue, 2012, "Penerapan Data Mining Market Basket Analysis Terhadap Data Penjualan Produk Buku Dengan Menggunakan Algoritma Apriori dan Frequent Pattern Growth (FP-Growth)," Jurnal TELEMATIKA MKOM, Vols. 4, No,1, pp. 118-132. 
[15]D. K. Pane, 2013, "Implementasi Data Mining Pada Penjualan Produk Elektronik Dengan Algoritma Apriori," Pelita Informatika Budi Darma, vol. 4 No.3, pp. 25-29.

[16]A. K. Prasidya and C. Fibriani, 2017, "Analisa Kaidah Asosiasi antar Item dalam Transaksi Pembelian Menggunakan Data Mining Dengan Algoritma Apriori," JUTI: Jurnal Ilmiah Teknologi dan Informasi, vol. 15 No.2, pp. 173-184.

[17]Suprayitno and U. I. Wardati, 2012, "Pembangunan Sistem Stok Barang dan Penjualan Pada Toko Sero Elektronik," IJCSS (Indonesian Jurnal on Computer Science Speed), vol. 3, no. Early Warning System , pp. 94-103.

[18]S. Pujiono, A. Amborowati and M. Suyanto, 2013, "Analisis Kepuasan Publik Menggunakan Weka Dalam Mewujudkan Good Governance di Kota Yogyakarta," Jurnal Dasi, p. 14.

[19]C. Budihartanti , 2013, "Penerapan Data Mining Berdasarkan Asosiasi Menggunakan Algoritma Apriori Dalam Penentuan Pola Belanja Kitchen Appliances," Techno Nusa Mandiri, p. 9. 